LLOYD, A. R., WAKEFIELD, D., Boughton, C., et al (1988) What is myalgic encephalomyelitis? Lancet, $i, 1286-1287$.

St Charles Hospital

London W10 6DZ

St Mary's Hospital

London

Dulwich Hospital

London

\section{Tardive dystonia: male:female ratio}

SIR: I read with interest the article by Cunningham Owens (Journal, May 1990, 156, 620-634), particularly the part about tardive dystonia, since in our clinic, we are studying this serious, often social, and sometimes physical, invalidating side-effect of neuroleptics. I was surprised by their comment that: "Also there is no known difference in prevalence between the sexes". Six publications suggest that, on the contrary, there is a difference in prevalence between the sexes showing male:female ratios as follows: Burke et al (1982), 2.5:1; Gimenez-Roldan et al (1985), 1.2:1; Friedman et al (1987), 4:1; Gardos et al (1987), 3:1. Yassa et al (1989), 3:1. This gives an average figure of 2.4 males to every female with tardive dystonia. Only one retrospective publication (125 patients, 30 with tardive dystonia) found an equal ratio for men and women (Miller \& Jankovic, 1990).

This difference in male:female ratio is probably one argument for considering tardive dystonia to be a separate entity from tardive dyskinesia, an opinion which has been suggested in several articles. As Yassa et al (1989) write: "tardive dystonia seems to be more common in young male patients while severe tardive dyskinesia is more common in older women".

BURKE, R. E., FAHN, S., JANKOVIC, J., et al (1982) Tardive dystonia: Late-onset and persistent dystonia caused by antipsychotic drugs. Neurology, 32, 1335-1346.

Gimenez-Roldan, S., Matbo, D. \& BARtolom, P. (1985)

Tardive dystonia and severe tardive dyskinesia: a comparison of risk factors and prognosis. Acta Psychiatrica Scandinavica, 71, $488-494$.

Friedman, J. H., Kurcharski, L. T. \& Wagner, R. L. (1987) Tardive dystonia in a psychiatric hospital. Journal of Neurology. Neurosurgery and Psychiatry, 50, 801-803.

GARDOs, G., Cole, J. O., SChuIEbolK, S., et al (1987) Comparison of severe and mild tardive dyskinesia: implications for etiology. Journal of Clinical Psychiatry, 48, 359-362.

YASSA, R., NAIR, V. \& IskandAR, H. (1989) A comparison of severe tardive dystonia and severe dyskinesia. Acta Psychiatrica Scandinavica, 80, 155-159.
Miller, L. G. \& JANKovic, J. (1990) Neurologic approach to druginduced movement disorders: a study of 125 patients. Southern Medical Journal, 83, 525-532.

Dr David Ricardo Capriles Clinic

Mohikanenweg 8, Curaçao

Netherlands Antilles

\section{Suicide risk for parasuicide repeaters}

SIR: Stocks \& Scott's retrospective study on people who repeatedly harm themselves deserves comment (Journal, March 1991, 158, 375-378). Their conclusion that people who repeatedly harm themselves are not as likely to die by suicide as has until now been thought cannot be sustained, and is dangerously misleading.

Their sample size was 42, and follow-up was only one year. The usual figure cited is that $1 \%$ of unselected hospital parasuicides kill themselves each year (Weissman, 1974). Using a follow-up period of only one year they would have needed more than 177 subjects with zero suicides to achieve a statistically significant result upon which they could conclude that the suicide rate in repeaters was less than the usual $1 \%$ rate (assuming a mean of 1 , a standard deviation of 0.3 and alpha equal to 0.05 ).

Alternatively, staying with this small sample size of 42 subjects they would have required 4.2 years of follow-up without a completed suicide to be able to claim a statistically significant lower death rate than 1 per 100.

Finally, 37 of their 42 subjects engaged in further self-harm within three months. We accept this is not surprising since they were selected as repeaters. What is surprising is their statement (with the obvious inference) that "Intervention, however problematic, may be justified if such patients are likely to kill themselves. None of the sample killed themselves ..." Hospital admission or other interventions may or may not be effective - little research has adequately addressed this issue. For the present, we have a problem of chronically suffering individuals imposing a considerable burden on emergency and other services. Intervention is justified!

Wesssman, M. M. (1974) The epidemiology of suicide attempts 1960-1971. Archives of General Psychiatry, 30, 737-746.

Division of Psychiatric Services

C. CANTOR

State Health Building

147-163 Charlotte Street

GPO Box 48, Brisbane 4001

Queensland, Australia

P. BURNETT

Queensland University of Technology, Australia 